\title{
The Effect of Rewards and Sanctions in Provision of Public Goods
}

\author{
Martin Sefton \\ University of Nottingham, United Kingdom \\ Robert Shupp \\ Ball State University, Muncie, IN \\ James Walker \\ Indiana University, Bloomington, IN
}

February 14, 2005

(C) 2005 Martin Sefton, Robert Shupp, James Walker

Acknowledgements: We thank Jeff Carpenter, Juan-Camilo Cardenas, Rachel Croson, Robyn Dawes, David Dickinson, Gerhard Glomm, Simon Gächter, Axel Ockenfels, Louis Putterman, Rupert Sausgruber, and Arlington Williams for their comments and advice and the Center on Philanthropy at Indiana University for funding support for this project.

Contact Details: Martin Sefton, School of Economics, University of Nottingham, Nottingham NG7 2RD, United Kingdom. e-mail: martin.sefton@ nottingham.ac.uk. tel: 44-115-846-6130; Robert Shupp, Department of Economics, Ball State University, Muncie, IN 47306. e-mail: rshupp@ bsu.edu.tel:765-285-3724; James Walker, Department of Economics, Indiana University, Bloomington, IN 47405. e-mail: walkerj @ indiana.edu. tel: 812-855-2760. 


\title{
The Effect of Rewards and Sanctions in Provision of Public Goods
}

\begin{abstract}
A growing number of field and experimental studies in social dilemma settings focus on the institutional arrangements by which individuals are able to solve collective action problems. Important in this research is the role of reciprocity and institutions that facilitate cooperation via opportunities for monitoring, sanctioning, and rewarding others. This study contrasts sanction and reward institutions in the context of a public goods experiment. Sanctions represent a net loss, a cost to both the participant imposing the sanction and the individual receiving the sanction. Rewards represent a zero sum transfer from participants giving rewards to those receiving rewards. These institutions are compared in regard to their impact on overall levels of cooperation and economic efficiency. (JEL C92)
\end{abstract}




\section{The Effect of Rewards and Sanctions in Provision of Public Goods}

The experimental literature on voluntary public goods provision shows that groups attain better outcomes than implied by economic models based on individuals maximizing ownmonetary earnings. At the same time, however, groups uniformly fail to achieve optimal outcomes, suggesting that incentives to free ride are important. Moreover, when the decision situation is repeated, the group outcome often deteriorates with repetition, suggesting that, in many settings, a groups' ability to overcome free rider incentives may be transitory (see for example Andreoni and Miller, 1993, Isaac, Walker, and Williams, 1994, and Croson, 1998).

In this paper we report an experiment examining the impact of introducing opportunities for individuals to reward or sanction other group members after observing their decisions. This institutional change is motivated by the observation that such opportunities are commonplace in field settings. In many group or team situations, individuals observe the actions of others, and individuals often have rich opportunities for reacting to others' behavior in ways that may impose costs or benefits on both parties. There is abundant anecdotal evidence that individuals sanction those who engage in selfish activities at the expense of other group members. For example, people who violate social norms are often ostracized. Similarly, there is strong anecdotal evidence that people are prepared to make sacrifices to help others on a quid pro quo basis. ${ }^{1}$ Recent experiments with simple proposer-responder games also demonstrate that responders are willing to depart from own-earnings maximization by rewarding more generous proposers or sanctioning less generous proposers (see Offerman, 2002, and Andreoni, Harbaugh and Vesterlund, 2003).

Given this evidence, the possibility that individuals will sanction or reward other group members, based upon their contributions to a public good, in a laboratory setting seems real. In 
turn, the possibility of receiving such sanctions or rewards may affect contributions. Such contributions could be viewed as a response to the threat of negative reciprocation, in the case of sanctions, or the expectation of positive reciprocation, in the case of rewards. Our experiment directly compares the effectiveness of such negative and positive reciprocation in maintaining contributions to public goods. ${ }^{2}$ In our experiment groups of four subjects make contribution decisions in a sequence of ten public goods games without opportunities to reward or sanction. These subjects then play a further ten games in which, at the end of each game, a second stage is added. Depending on treatment, in the second stage subjects are given an opportunity to (i) neither reward nor sanction, (ii) reward, (iii) sanction, or (iv) both reward and sanction, other group members on the basis of their contribution decisions.

When neither rewards nor sanctions are available, our results mirror those of previous experiments: contributions and earnings steadily diminish with repetition. In the other treatments the introductions of opportunities to reward and/or sanction initially increase contributions. However, in the reward treatment contributions subsequently decrease to a level below that observed in the absence of opportunities to reward. Thus, the opportunity to reward by itself is insufficient to sustain contributions. In contrast, we find that sanctioning sustains public goods provision at a level above that observed in the absence of sanctioning opportunities, and so sanctioning appears to be a more effective mechanism for sustaining contributions. However, opportunities to sanction initially result in a loss of efficiency, as the direct costs associated with sanctioning outweigh the effect of increased contributions. Only in later rounds, where it appears that the mere threat of being sanctioned sustains contributions does the opportunity to sanction enhance group performance. Our treatment allowing both sanctions and rewards suggests a 
synergistic relationship between the two, insofar as this treatment generates the highest contributions and earnings.

Our data also allow us to make some observations about the way rewards and sanctions are used. Those subjects most willing to use rewards and sanctions are those who contribute more than the group average, and subjects who contribute more (less) that the group average are more likely to receive rewards (sanctions). We also observe, however, differences in the dynamic patterns of rewarding/sanctioning behavior. While initially subjects use rewards more frequently than sanctions, over time the use of rewards steadily diminishes, so that in later rounds they are used less frequently than sanctions.

The remainder of the paper is organized as follows. In the next section, we describe the nature of sanctions and rewards in the public goods laboratory setting. In Section II, we describe the specific experimental setting investigated here and Section III presents the experimental results. Section IV contains concluding comments.

\section{Rewards and Sanctions in Public Goods Experiments}

Our setting for studying public goods provision is the voluntary contributions mechanism (VCM) with linear payoffs. ${ }^{3}$ In this setting, subjects are endowed with tokens that they can allocate between a private account and a group account. The returns from these accounts are structured so that group earnings are maximized when subjects allocate all their tokens to the group account. Private monetary incentives, however, point individuals toward placing all their tokens in their private accounts. The stylized results emerging from this type of decision setting are: a) there is considerable heterogeneity in individual allocations, b) allocations to the group account exceed the prediction of zero tokens, but are substantially below the optimal level of 
$100 \%$ of endowments, and c) group allocations often decline significantly as the game is repeated.

These findings suggest the need for understanding the effectiveness of alternative institutional arrangements to facilitate group cooperation. Ostrom, Walker and Gardner (1992), investigate behavior in a related common-pool resource game, and find that covenants or promises about future actions can be useful in maintaining cooperation, even when the promises are non-binding. ${ }^{4}$ They also study the effect of supporting covenants with sanctions. They find that covenants are even more effective when supported by internal sanctions, i.e. sanctions imposed by group members. On the other hand, they find that sanctions used alone, without covenant opportunities, may actually lower group earnings when costs of sanctions are included.

Our study is most closely related to that of Fehr and Gächter (2000). They investigate a 2-stage punishment game. The first stage corresponds to a single period of the VCM game. In the second stage, individual decisions are anonymously revealed to the group and subjects have an opportunity to punish each other. Punishment is costly, both to the person doing the punishment and the person being punished. ${ }^{5}$ Public goods provision is significantly higher in the VCM game with opportunities to sanction than in the VCM game without opportunity for sanctions. Once the costs of sanctioning are taken into account, however, the welfare implications are somewhat ambiguous. In their partners treatment, which most closely parallels the experiments reported here, payoffs in the first decision round are lower than in the first period of the VCM game without sanctions. By the last period, however, the game with sanctions offers a payoff gain of approximately $20 \%$ relative to the VCM game without sanctions. 
Our experiment builds on these two studies by contrasting sanction opportunities with reward opportunities. Analogous to the sanctioning game, the reward game is structured so that it is costly to reward other group members. Note this implies that withholding a reward is not equivalent to sanctioning, as the former increases own earnings whereas the latter reduces own earnings. Thus sanctions reduce the earnings of both the subject imposing the sanction and the subject being sanctioned, whereas rewards simply constitute a transfer of earnings from the subject giving the reward to the subject receiving the reward. In particular, while sanctions directly reduce group earnings, rewards allow individual group members to react to others' contributions without impinging on efficiency.

This asymmetry in how rewards and sanctions affect payoffs suggests at least two reasons why the behavioral effects of rewards and sanctions might differ. First, if the threat of sanctioning free riders induces cooperation then sanctions need not be used, whereas if the promise of rewarding contributors induces cooperation then rewards must be used. Second, sanctions can be used by contributors to 'get even' with free riders, but rewards cannot. That is, the earnings advantage of a free rider over other group members can be reduced if the other group members use sanctions against the free-rider, but not if the other group members reward one another.

\section{The Decision Setting}

The initial study includes twelve sessions. In each session, twelve subjects were recruited from introductory economics classes at Indiana University-Bloomington. ${ }^{6}$ Via the computer, the twelve subjects were privately and anonymously assigned to four-person groups and remained in these groups throughout the session. No subject could identify which of the others in the room was assigned to their group. Since no information passed across groups, each session involved 
three independent groups. At the beginning of each session, subjects privately read a set of instructions. ${ }^{7}$ A review of the instructions was then presented on an overhead screen so that the structure of the decision problem was public information. Subjects made all decisions privately. There were four treatment conditions: sanction, reward, sanction\&reward, and baseline. Table 1 presents summary design information. Three sessions were conducted using each of the four treatment conditions, yielding data on 9 independent 4-person groups in each condition. ${ }^{8}$

Each group participated in two sequences of ten decision rounds, Sequence I and Sequence II. The structures of Sequence I and Sequence II were explained prior to beginning Sequence I. In all sessions and all treatment conditions, each round in Sequence I corresponded to a VCM game. At the beginning of each Sequence I decision round, each subject was endowed with six tokens to be allocated between their private account and the group account. For each token placed in his or her private account a subject received 10 cents. For each token placed in the group account, each group member received 5 cents. After all subjects had made their decisions for a round, they were informed of the aggregate allocations to the group account, the allocation of each member of their group to the group account, and their own earnings for the round. Individual decisions were not linked to subject identifiers and the order in which other group member's decisions were presented on each subject's terminal was randomized each round. Thus, subject-specific reputations could not develop across rounds. This parallels the setting used by Fehr and Gachter (2000).

Each round of Sequence II contained two stages. Stage 1 of each round involved a VCM game identical to that used in Sequence I decision rounds. The structure of Stage 2 varied across the four treatment conditions. In Stage 2 of each round of the sanction treatment, each subject was endowed with six additional tokens, which could be allocated to a private account, from 
which the subject earned 10 cents per token, or used to sanction other group members. The computer screen informing a subject of other group members' Stage 1 decisions was used for imposing sanctions. Alongside each group member's decision, subjects could indicate how many of their six tokens they wished to use to sanction each particular group member. Because the decisions of others were ordered randomly each round and did not contain subject identifiers, subjects could sanction only on the basis of current round decisions. For each token used to sanction another group member, that group member's earnings were reduced by 10 cents. The cost to the individual imposing the sanction was the foregone earnings from their own private account. Thus, each token used for sanctioning reduced group earnings by 20 cents. After sanctioning decisions were completed, each subject was informed of their earnings, including any sanctions they imposed or received. Subjects were informed of the total number of sanctions they received, but could not identify which of the other subjects imposed the sanctions. Further, subjects were not informed of the number of sanctions other group members received.

Stage 2 of the reward treatment was identical to the sanction treatment, except instead of using tokens to sanction other group members, subjects could use tokens to reward other group members. Subjects using tokens to reward other group members incurred a cost in the form of foregone earnings. However, for each token used to reward a group member, that group member received 10 cents. Thus, rewards constituted a pure redistribution of earnings.

In the sanction\&reward treatment, both sanctions and rewards were allowed. Tokens could be allocated toward sanctions in which case the subject receiving the sanction had his earnings reduced by 10 cents, or allocated toward rewards in which case the subject receiving the reward has his earnings increased by 10 cents. 
Opportunities for learning, or for employing history-dependant strategies, make it problematic to use comparisons of the Sequence I and Sequence II decisions to measure the effect of sanctions and rewards. Thus, for purposes of experimental control, a baseline treatment was also conducted. All aspects of the baseline treatment were identical to the other treatments, except that there were no opportunities for rewards or sanctions, and no language in the instructions related to opportunities to reward or sanction. ${ }^{9}$

With this design subjects play a finitely repeated game with a commonly known final round. Under the assumption that it is common knowledge that subjects maximize own-earnings, the theoretical predictions for our treatments are straightforward. The subgame perfect Nash equilibrium for each treatment condition calls for zero contributions in the VCM game and no sanctions or rewards. ${ }^{10}$ As noted earlier, however, experimental studies of the VCM game typically find that the level of cooperation observed is not consistent with equilibrium predictions of zero provision of the group good. ${ }^{11}$ Moreover, recent studies have shown that subjects do use sanctions - even though they reduce own-earnings - when they are available (see, for example, Fehr and Gächter, 2000, or Masclet, Noussair, Tucker and Villeval, 2003).

To the extent that motivations of fairness and reciprocity do play a role in decisionmaking, the sanction and reward decision environments investigated here allow for subjects to act on such motivations beyond changes that they make in their group allocations to the public good. ${ }^{12}$ That is, in the setting here, subjects can respond via explicitly targeted sanctioning or rewarding behavior. Sanctions and rewards can be viewed as an extension of reciprocal behavior allowed through contribution decisions in the standard VCM game. Subjects make costly decisions that yield signals to others that are specifically targeted in relation to current round decisions. 


\section{Results}

Group-level data is first analyzed to assess the effect of rewards and sanctions on levels of provision of the public good and overall earnings. We then examine overall levels of rewards and sanctions and analyze rewarding and sanctioning behavior at the individual level. Summary results are also presented from additional experimental sessions conducted to examine the effects of changing the number of decision rounds and framing of instructions. ${ }^{13}$

\section{A. Treatment Effects}

\section{Allocations to the group account}

Figure 1 displays average group allocations across all twenty rounds. Data is presented as the percentage of tokens allocated to the group account. Recall, prior to making any decisions, subjects were informed of the decision environment for both Sequence I and Sequence II. In the reward, sanction, and sanction\&reward treatments, the pattern of average group allocations across Sequence I (round 1 to 10) is very similar to the baseline treatment. This evidence suggest that instructions that vary across treatment conditions for Sequence II have no differential impact on decisions in Sequence I. ${ }^{14}$ Further, pooling across treatment conditions, the pattern of group allocations is consistent with that observed in previous studies. In the initial round, subjects allocate an average of $53 \%$ of endowments to the group account. Group allocations then decline across rounds to $44 \%$ in round ten. Even in the final round of Sequence I, group allocations substantially exceed the zero allocation level based on the standard model of own-earnings maximization. $^{15}$

As shown in Figure 1, the time trends of average group allocations diverge across treatments in Sequence II. Most notably, average group allocations in the reward, sanction, and sanction\&reward treatments move away from the baseline treatment over early rounds of 
Sequence II. In the baseline treatment there is a restart effect -- group allocations are higher in round 11 than round 10 -- and then allocations resume their downward trend. In the sanction and sanction\&reward treatments, allocations increase and are sustained above $50 \%$ throughout Sequence II. Both treatments, however, show an end of experiment decay in group allocations, with the decay in the sanction\&reward treatment beginning in round 19. The data reveal a similar, but more pronounced, dynamic in the reward treatment. Group allocations are well above the baseline for most of Sequence II, but in round 17 begin a sharp decay. By the last round, group allocations fall below that of the baseline.

Statistical tests bear out the trends displayed in Figure 1. Group allocations in round eleven are not significantly different across treatments at conventional levels; allocations in the final round, as well as across all rounds of Sequence II, are significantly different. ${ }^{16}$ Considering each treatment separately, contributions in round 20 are significantly lower than in round 11 for the baseline and reward treatments $(\mathrm{p}=0.0195$ and 0.035 respectively, using a one-sided sign test), but not for the sanction $(\mathrm{p}=0.500)$ or sanction\&reward $(\mathrm{p}=0.637)$ treatments. Comparing the baseline and reward treatments, contributions are not significantly different in rounds 11 or 20 , but differ at the $10 \%$ significance level when we compare average contributions over Sequence II, reflecting the temporary increase in contributions resulting from the introduction of rewarding opportunities. ${ }^{17}$ In contrast, a pairwise comparison of the baseline and reward\&sanction treatments shows that a significant difference in contribution levels emerges and is sustained in the course of Sequence II. ${ }^{18}$ The difference between the baseline and sanction treatments is less pronounced, and indeed not significant at conventional levels (even though, as already noted, contributions exhibit different dynamics in the two treatments). ${ }^{19}$ 


\section{Group Efficiency}

Efficiency in allocations is defined as group earnings as a percentage of maximum possible earnings. Given that allocations are very similar across treatments in Sequence I, earnings and efficiencies are also, averaging $78 \% .^{20}$ In Sequence II, the divergent patterns in allocations and the use of rewards and sanctions generate differences in earnings, and resulting efficiencies. Following round 11, the initial impact of allowing rewards and/or sanctions is a shift upwards in efficiencies in the reward and sanction\&reward treatments relative to the baseline, and a downward shift in the sanction treatment. As shown in Figure 2, however, efficiencies follow a different dynamic across the treatment conditions. Efficiencies in the sanction\&reward treatment remain relatively stable, while efficiencies in the sanction treatment show a statistically significant increase, from round 11 to 20 . Efficiencies in the reward treatment are relatively stable until round 17 , where they begin a sharp decline. ${ }^{21}$

\section{B. How Sanctions and Rewards are Used}

As well as allowing a comparison of the effects of rewards and sanctions on group allocations and earnings, our data supplies some evidence about how rewards and sanctions are actually used. Figure 3 displays the average percentage of tokens used for sanctions/rewards across rounds. As seen in the left-hand panel, in the sanction treatment, subjects begin by allocating on average $31 \%$ of their second stage tokens to sanctions, but this percentage falls to $16 \%$ by the final round. The decline in the use of rewards is more pronounced. In the reward treatment, tokens used for rewarding falls sharply, from $41 \%$ of endowments in round 11 to $3 \%$ in the final round. The right-hand panel of Figure 3 displays the use of rewards and sanctions in the sanction\&reward treatment. Again, subjects initially prefer using rewards to sanctions. In round $11,42 \%$ of endowments are allocated to rewards and only $8 \%$ to sanctions. However, this 
pattern is not maintained. In the final round only $8 \%$ of endowments are used for rewarding other subjects, and $10 \%$ for sanctioning. ${ }^{22}$

For further analysis of rewarding and sanctioning behavior we focus on three issues: (1) who sanctions or rewards, (2) recipients of sanctions or rewards, and (3) the impact of sanctions or rewards on the distribution of earnings.

\section{Who Sanctions/Rewards}

To examine the characteristics of individuals who use sanctions/rewards we use a Tobit specification. The dependent variable is an individual's expenditures on sanctions/rewards in a given round, and the explanatory variables are the individual's allocation to the group account in that round and the average allocation by that individual's group in that round. Round and group dummies are also included to capture time and group fixed effects. The results are shown in Table 2 . The primary conclusions of this analysis are rather intuitive. Holding the group's average allocation fixed, those individuals who allocate most to the group account tend to sanction/reward most. Holding own allocation fixed, individuals in groups that allocated less to the group account do more sanctioning, and less rewarding.

\section{Recipients of Sanctions/Rewards}

We next examine the characteristics of subjects who receive sanctions/rewards. In order to account for the fact that subjects could receive both sanctions and rewards in the sanction\&reward treatment, we calculate net reward as the difference between reward received and sanction received. Following an approach similar to that used by Fehr and Gachter (2000), Figure 4 shows net rewards received as a function of an individual's deviation from the average group allocation of other group members. Deviations are grouped into intervals, and the average net reward received over observations falling in each interval is plotted. 
Our data support Fehr and Gacther's interpretation of the determinants of being sanctioned. In the sanction treatment, subjects are more heavily sanctioned the further their own allocation to the group account falls below the average allocation of the rest of their group. As observed by Fehr and Gächter and Ostrom, Walker and Gardner (1992), however, there is some sanctioning of those making group allocations well above the group average. ${ }^{23}$ In the sanction\&reward treatment, those making group allocations well below the average of other group members are sanctioned, but not at the level observed in the sanction treatment. As expected, those in the reward treatment that make allocations above the average of other group members receive the abundance of the rewards. Interestingly, however, the average rewards for those making group allocations well above the average of other group members are no greater than for those just above the average of others. Further, large deviations below the average of other group members were sanctioned at a magnitude much higher than rewards for allocations well above the average of other group members.

To characterize the determinants of rewards and sanctions more formally, we estimate a model similar to that used by Fehr and Gächter. We use a Tobit specification with net reward received as the dependent variable, and others' average group allocation, and negative and positive deviations from this, as explanatory variables. ${ }^{24}$ The results are presented in Table 3 . In the sanction treatment, higher negative deviations are punished more, consistent with the findings of Fehr and Gächter. However, neither "others' average allocation" nor "absolute positive deviation" is statistically significant. This differs from the results of Fehr and Gächter, where "others' average allocation" is significant. In the regression for the sanction\&reward treatment, net rewards are positively correlated with others' average allocation, higher negative deviations lead to higher sanctions, and higher positive deviations lead to higher rewards. Note, 
that, consistent with the results reported above, holding constant the size of the deviation, negative deviations lead to higher sanctions than rewards for positive deviations. Similarly, in the reward treatment, rewards are higher in those groups in which other group members allocate more, and are positively correlated with one's own group allocation as a deviation from that of others in one's group.

\section{Distribution of Individual Earnings}

Sanctions and/or rewards have the potential to impact the distribution of earnings beyond earnings differences that are attributable to variations in endowment allocation decisions across individuals and groups. The analysis above examined the characteristics of subjects who received sanctions/rewards. To examine how these factors combine to impact overall earnings and earnings distributions within treatment conditions, we compute each subject's total earnings, pooled across rounds 11-20. In summary, based on several measures of dispersion, convincing evidence is found that the sanction treatment leads to greater income inequality than the other treatments. The sanction treatment includes the widest range of incomes, the highest variance, and the largest Gini-coefficient. ${ }^{25}$ Further, it is interesting to note that in the treatments that allow sanctions/rewards, the variability in earnings that include sanctions/rewards (earnings from Stage 1 and Stage 2) exceeds the variability in earnings computed before sanctions and rewards are included (earnings after Stage 1). ${ }^{26}$ Thus, earnings inequalities are actually increased with the opportunity to sanction and reward.

\section{Additional Experiments - Time horizon and Framing}

In the final part of this section, we report results from additional experiments that were conducted to examine the robustness of the results of our initial study. First, the results presented above suggested that in the reward treatment there was a strong tendency for improvements in 
efficiency to be negated with repetition, especially in later decision rounds. In contrast, it appears that subjects, over time, were able to use the sanctioning environment to begin a process of efficiency enhancement. These results led us to question whether a longer time horizon might yield a clearer picture of differences in these two institutional settings. To explore this we conducted an additional session of both the reward and the sanction treatments, but with 20 rounds in Sequence II instead of 10.

The results from these sessions are summarized in Figure 5 and are strikingly similar to those from our original design. Averaging over groups, in the sanction treatment there is a modest increase in allocations to the group account in rounds 11-30 compared to 1-10. In the reward treatment, group allocations increase initially relative to their level in round 10, but decay over time, particularly in the last five rounds. Not surprisingly, there is no discernible improvement in efficiencies. Finally, similar to the patterns observed in our initial data, in both treatments one observes a significant decay in the number of rewards and sanctions across rounds, with the larger decay being observed in the reward treatment.

Second, it is possible that behavior may be sensitive to the way opportunities to sanction/reward are presented to subjects. Our instructions specifically included terminology that referred to opportunities to 'sanction' or 'reward' others. To investigate whether this framing may have had an impact on behavior, we ran two additional sessions, six 4-person groups, of our sanction\&reward treatment. These sessions replaced references to 'sanctions' and 'rewards' with wording that simply referred to opportunities to decrease or increase others' earnings.

Figure 6 summarizes average allocations to the group account and the use of rewards and sanctions in these sessions. Compared to our initial study, the average level of allocations to the group account was somewhat lower. However, we guard against attributing this difference to the 
neutral language frame since the average level was lower than even our initial baseline condition, in which there were no opportunities to sanction or reward and no use of language that referred to opportunities to sanction/reward. In round 1 of Sequence I, group allocations averaged $39 \%$ and declined to $21 \%$ by round 10 . As with our initial data, however, there is considerable variation across groups. In the first round of Sequence II, where subjects had the opportunity to reward or sanction others, average group allocations increased to $32 \%$ and gradually increased to $42 \%$ by round 20 . Thus, the general pattern of change in group allocations is similar to that observed in the sanction\&reward treatment in the initial study. Further, the use of rewards and sanctions in these sessions is very similar to that observed in the original sanction\&reward sessions. Initially, subjects use rewards more frequently than sanctions, using $33 \%$ of their endowment for rewarding and $17 \%$ for sanctioning. By the final round, subjects used $8 \%$ of their endowment for rewards, and $8 \%$ for sanctions. Given the similar use and effect of sanctions and rewards in these additional experiments, it appears that the conclusions drawn in our initial study are robust to these changes.

\section{Concluding Comments}

Experiments on the provision of public goods offer a rich testing ground for examining norms of behavior and how such behavior is impacted by alternative institutional arrangements. In particular, this paper focuses on reciprocity as a behavioral norm, examining changes in individual group allocations as a general form of reciprocity and sanctions and rewards as targeted forms of reciprocity.

Our results show that rewards and sanctions are not symmetric in their behavioral effects: opportunities to reward or sanction are used differently by subjects and have different consequences for facilitating cooperation. ${ }^{27}$ Initially, subjects chose to use rewards more than 
sanctions. However, the rate of decay in the level of rewards was faster than that for sanctions. Subjects appeared to "give up" more quickly on the use of rewards. Further, sanctions appeared to be imposed in a more intuitive way than rewards. There was a clear positive correlation between the number of sanctions received and the degree to which an individual's group allocation was below that of other group members. Rewards were generally given to those with group allocations above the average of others, but the magnitudes varied little with how far an individual's group allocation was above the average of others, suggesting that there was not a clear consensus on how rewards should be used. The opportunity to reward other group members led to a modest increase in group allocations and earnings, although this was due to behavior in initial rounds that did not survive repetition. On the other hand, in treatments that allowed sanctions, groups were better able to sustain group allocations, although the beneficial impact on earnings was hindered by the cost of sanctions.

These results lend some support to arguments that the use of sanctions may be necessary to promote cooperation initially, but the threat of sanctions may be sufficient to sustain cooperation. These results also point to the complexities involved in using a reward system for sustaining cooperation. One might argue that a successful reward system requires continued use of rewards, and those rewards must be in the form of transfers from those allocating less to the public good to those allocating more. In our experiments, however, it was those subjects who allocated relatively more to the group account who tended to give more rewards. Further, as noted above, it appears that subjects lacked a clear focal point or consensus in regard to where rewards should be targeted. The significant decay in rewards across decision rounds, suggests that groups may have difficulty in maintaining a rewards system. 
The results from the sanction treatment of this study are qualitatively consistent with those of Fehr and Gächter (2000) and other recent studies that examine sanctioning. Subjects use sanctions and overall group allocations increase. The primary behavioral difference among these studies is the degree to which sanctions increase group allocations and the extent to which increased group allocations succeed in increasing overall earnings. There are structural differences among these studies that might account for this difference. In particular, some studies follow Fehr and Gachter and employ parameterizations where subjects faced convex costs of imposing sanctions (Carpenter, 2000, and Masclet, Noussair, Tucker, and Villeval, 2003). In these studies, it was relatively inexpensive to assign a small number of sanctions to another group member. Further, each unit of sanction reduced earnings by a fixed percentage. Thus, in absolute terms, sanctions reduced earnings more for high earners. Others, like the study here, use a simpler linear framework (Yamagishi, 1986, Bochet, Page and Putterman, forthcoming). In this case, there is a one-to-one mapping from costs of imposing a sanction to the magnitude of the sanction. The weaker effect of sanctions in our study may reflect the intuitive notion that sanctions will be more readily used when they are less costly to impose, and will be more effective when they impose greater costs upon those sanctioned. ${ }^{28}$

The one-to-one nature of our sanctioning technology limits the ability of subjects to use sanctions to reduce disadvantageous payoff inequality (in the sense of Fehr and Schmidt, 1999). ${ }^{29}$ Even so, subjects do use sanctions in our experiment. In this respect, our results support Falk, Fehr and Fischbacher's (2001) findings from a 'low-sanction' Prisoner's Dilemma experiment, which also employs a one-for-one sanctioning technology. They observe a substantial number of subjects cooperating and sanctioning defectors, and interpret the driving force behind these sanctions to be a desire to retaliate against unfair behavior, rather than to 
reduce unfair payoff differences. In this sense, our experimental results complement a growing number of experimental studies of public goods provision that find support for behavior based on reciprocity or conditional cooperation. Future theoretical work, and experimental tests of these theories, face the challenge of more clearly articulating the scope of these norms of reciprocity, as well as how these norms vary and interact across individuals and across institutional arrangements. 


\section{References}

Ahn, T.K., Ostrom, E., and Walker, J., 2002. "Incorporating Motivational Heterogeneity into Game Theoretic Models of Collective Action," Working paper, Workshop in Political Theory and Policy Analysis, Indiana University, 2002.

Andreoni, J., 1988. "Giving with Impure Altruism: Applications to Charity and Ricardian Equivalence," Journal of Political Economy, Vol. 97, 1447-1458.

Andreoni, J., Harbaugh, W., Vesterlund, L., 2003. "The Carrot or the Stick: Rewards, Punishments and Cooperation," American Economic Review, 93(3), 893-902.

Andreoni, J., Miller, J., 1993. "Rational Cooperation in the Finitely Repeated Prisoner's Dilemma: Experimental Evidence." Economic Journal, Vol. 103, 570-585

Bochet, O., Page, T., Putterman, L., forthcoming. "Communication and Punishment in Voluntary Contribution Experiments," Journal of Economic Behavior and Organization.

Bolton, G.E., Ockenfels, A., 2000. "ERC: A Theory of Equity, Reciprocity, and Competition.” American Economics Review, 90, 166-193.

Coats, J., Neilson, W., 2000. "Uncovering Beliefs about Opponents' Preferences in Sequential Games," Working paper, Texas A\&M University.

Carpenter, J., 2000. "Mutual Monitoring in Teams: Theory and Experimental Evidence," Working Paper, Middlebury College.

Clark, K., Sefton, M., 2001. "The Sequential Prisoners Dilemma: Evidence on Reciprocation," Economic Journal, Vol. 111, 51-68.

Croson, R., 1998. Theories of Commitment, Altruism and Reciprocity: Evidence from Linear Public Goods Games. Working Paper, OPIM Department, The Wharton School, University of Pennsylvania.

Dickinson, D., 2001. "The Carrot vs. the Stick in Work Team Motivation," Experimental Economics, 4, 107-124.

Falk, A., Fehr, E., Fischbacher, U., 2001. Driving Forces of Informal Sanctions. Working Paper, Institute for Empirical Research, University of Zurich, Switzerland.

Falk, A., Fischbacher, U., forthcoming. "A Theory of Reciprocity," Games and Economic Behavior.

Falkinger, J., Fehr, E., Gächter, S., Winter-Ebmer, R., 2000. "A Simple Mechanism for the Efficient Provision of Public Goods - Experimental Evidence", American Economic Review, 90, 247-264. 
Fehr, E., Gächter, S., 2000. "Cooperation and Punishment in Public Goods Experiments," American Economic Review, 90, 4, 980-994.

Fehr, E., Schmidt, K., 1999. "A Theory of Fairness, Competition, and Cooperation", Quarterly Journal of Economics 114, 817-868.

Gunnthorsdottir, A., Houser, D., McCabe, K., Ameden, H., 2000. "Excluding free-riders improves reciprocity and promotes the private provision of public goods." Working Paper, University of Arizona, Tucson.

Hoffman, E., McCabe, K., Smith, V., 1998. "Behavioral foundations of reciprocity: experimental economics and evolutionary psychology." Economic Inquiry 36, 335-352.

Isaac, M., Walker, J., Williams, A., 1994. "Group Size and the Voluntary Provision of Public Goods: Experimental Evidence Utilizing Large Groups," Journal of Public Economics, 54, pp. 1-36.

Isaac, M., Walker, J., 1988. "Communication and Free Riding Behavior: The Voluntary Contribution Mechanism," Economic Inquiry, October 1988, 585-608.

Kerr, N., 1999. "Anonymity and social control in social dilemmas". In M. Foddy et al. (Eds.), Resolving Social Dilemmas Philadelphia, PA, Psychology Press, 103-119.

Keser, C., 1997. "SUPER: Strategies Used in Public Goods Experimental Rounds," working paper.

Keser, C., 1999. "Cooperation in Public Goods Experiments," working paper.

Ledyard, J., 1995. "Public Goods: A Survey of Experimental Research," in Kagel, J. and A. Roth (eds) Handbook of Experimental Economics, Princeton University Press.

Masclet, D., Noussair, C., Tucker, S., Villeval, M., 2003. "Monetary and Non-Monetary Punishment in the Voluntary Contributions Mechanism," American Economic Review, 93 (1), 366-380.

Offerman, T., 2002. Hurting Hurts more than Helping Helps, European Economic Review, 46, 1423-1437.

Oliver, P., 1980. "Rewards and Punishments as Selective Incentives for Collective Action: Theoretical Investigations," American Journal of Sociology, Vol. 85, No. 6, pp 13561375.

Orbell, J., van de Kragt, A., Dawes, R., 1988. "Explaining Discussion Induced Cooperation," Journal of Personality and Social Psychology, 54 (5), 811-819.

Ostrom, E., 1990. Governing the Commons, Cambridge University Press. 
Ostrom, E., Walker, J., Gardner, R., 1992. "Covenants with and without a Sword: SelfGovernance is Possible," American Political Science Review, 86, 404-417.

Schmidt, D., Shupp, R., Walker, J., Ahn, T., Ostrom, E., 2001.“Dilemma Games: Game Parameters and Matching Protocols," Journal of Economic Behavior and Organization, Vol. 1335, 1-20.

Seely, B., Van Huyck, J., Battalio, R., forthcoming. Credible Assignments Can Improve Efficiency in Laboratory Public Goods Games, Journal of Public Economics.

Sonnemans, J., Schram, A., Offerman, T.,1999. Strategic behavior in public good games: when partners drift apart. Economics Letters 62, 35-41.

Sugden, R., 1984. "Reciprocity: The Supply of Public Goods Through Voluntary Contributions," The Economic Journal, December, 772-787.

Swope, K., 2002. "An Experimental Investigation of Excludable Public Goods," Experimental Economics, 5(3), 209- 222.

Yamagishi, T., 1986. “The Provision of a Sanctioning System as a Public Good,” Journal of Personality and Social Psychology, Vol. 51, No. 1, 110-116. 


\begin{tabular}{|c|c|c|c|c|}
\hline \multicolumn{5}{|c|}{ Table 1. Design Information } \\
\hline Treatment & $\begin{array}{c}\text { Sequence I } \\
\text { (Rounds 1-10) }\end{array}$ & $\begin{array}{c}\text { Sequence II } \\
\text { (Rounds 11-20) }\end{array}$ & $\begin{array}{c}\text { Number of } \\
\text { Sessions }\end{array}$ & $\begin{array}{c}\text { Number of } \\
\text { Independent Groups }\end{array}$ \\
\hline baseline & VCM & VCM & 3 & 9 \\
\hline sanction & VCM & VCM/sanction & 3 & 9 \\
\hline reward & VCM & VCM/reward & 3 & 9 \\
\hline sanction\&reward & VCM & $\begin{array}{c}\text { VCM/sanction or } \\
\text { reward }\end{array}$ & 3 & 9 \\
\hline
\end{tabular}

Table 2. Individual Expenditures on Sanctions and Rewards

\begin{tabular}{|l|c|c|c|c|}
\hline & \multicolumn{2}{|c|}{$\begin{array}{c}\text { Dependent Variable: } \\
\text { Expenditures on Sanctions }\end{array}$} & \multicolumn{2}{c|}{$\begin{array}{c}\text { Dependent Variable: } \\
\text { Expenditures on Rewards }\end{array}$} \\
\hline Independent Variables & sanction & $\begin{array}{c}\text { sanction\&rewar } \\
d\end{array}$ & reward & sanction\&reward \\
\hline $\begin{array}{l}\text { Average Allocation to Group } \\
\text { Account by Group }\end{array}$ & $-0.7257^{* *}$ & $-2.5332^{* * *}$ & 0.1995 & $1.8453^{* * *}$ \\
\hline Allocation to Group Account & $0.7586^{* * *}$ & $0.7902^{* * *}$ & $0.2715^{* * *}$ & -0.2929 \\
\hline
\end{tabular}

Note: Tobit maximum likelihood estimates. Group and round dummies were also included as independent variables. A* denotes significance at 5\% level, $* *$ at $1 \%$ level, $* * *$ at $0.1 \%$ level.

Table 3. Recipients of Sanctions or Rewards

Dependent variable: Net Rewards Received

\begin{tabular}{|l|c|c|c|}
\hline Independent Variables & sanction & reward & sanction\&reward \\
\hline $\begin{array}{l}\text { Others' Average } \\
\text { Allocation }\end{array}$ & 0.4597 & $0.5316^{* * *}$ & $0.7495^{* * *}$ \\
\hline $\begin{array}{l}\text { Absolute Negative } \\
\text { Deviation }\end{array}$ & $-1.8548^{* * *}$ & $-0.8623^{* * *}$ & $-1.2488^{* * *}$ \\
\hline $\begin{array}{l}\text { Absolute Positive } \\
\text { Deviation }\end{array}$ & 0.2233 & $0.6262^{* * *}$ & $0.3115^{* *}$ \\
\hline
\end{tabular}

Note: Tobit maximum likelihood estimates. Group and round dummies were also included as independent variables. ${ }^{*}$ denotes significant at $5 \%$ level, $* *$ at $1 \%$ level, $* * *$ at $0.1 \%$ level. 


\section{Figure 1. Allocations to Group Account}

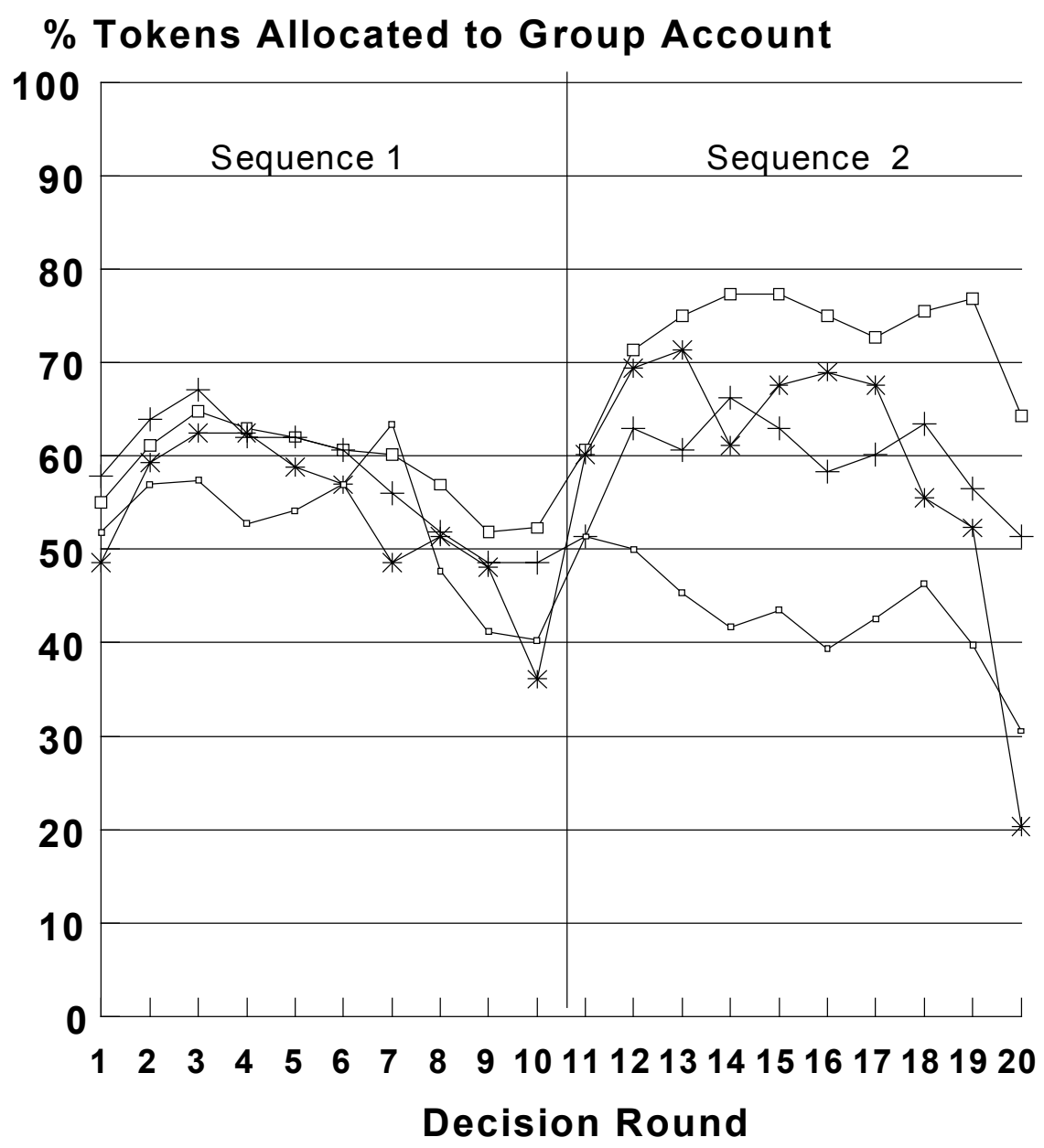

$\begin{array}{ll}-\rightarrow \text { baseline } & + \text { sanction } \\ * \text { reward } & -- \text { sanction\&reward }\end{array}$


Figure 2. Efficiency: Earnings as a \% of Maximum

Sequence II Observations

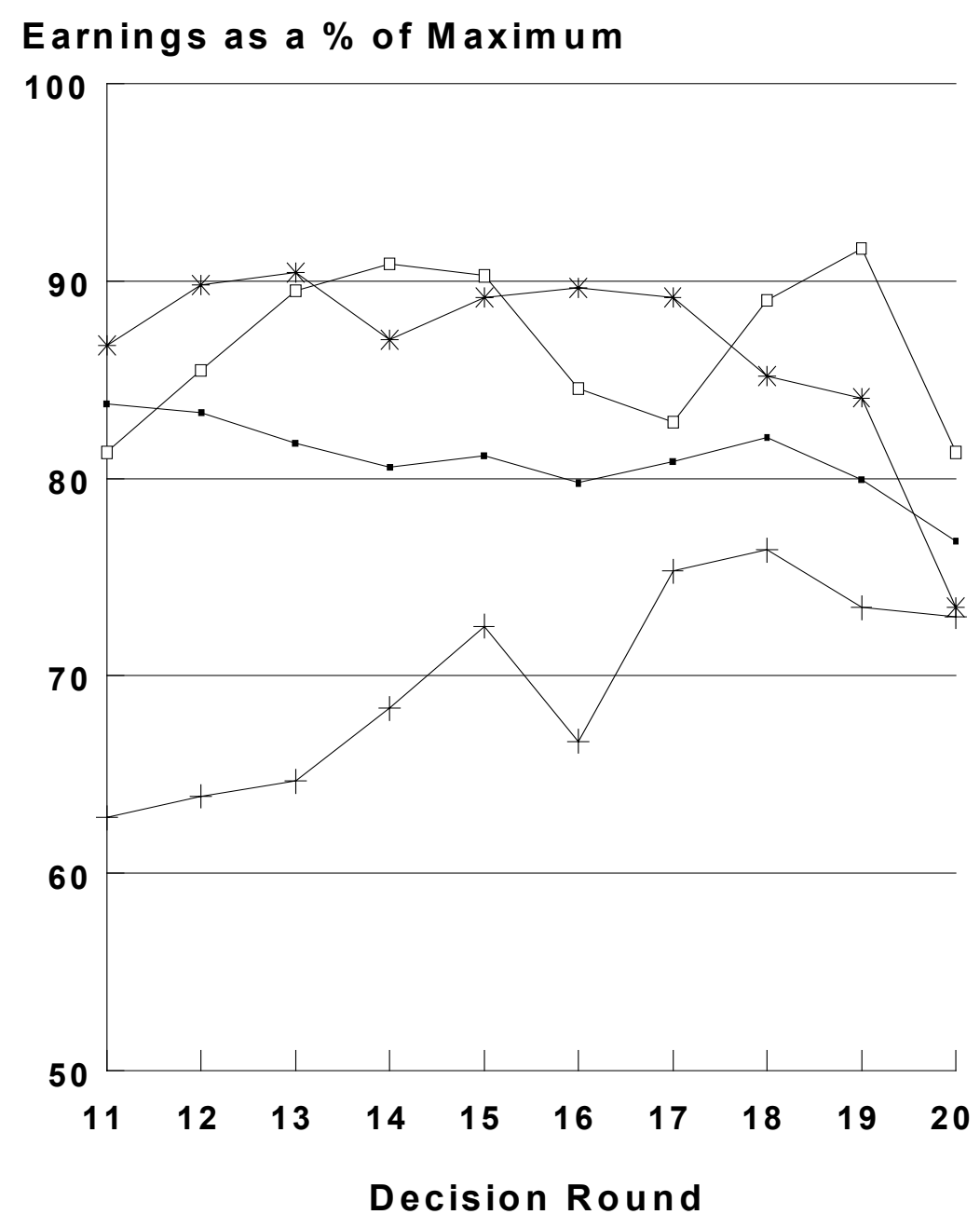

\begin{tabular}{lll|}
\hline baseline & + sanction \\
$*$ reward & - & sanction\&reward
\end{tabular}




\section{Figure 3. Tokens Used for Sanctions and/or Rewards}

\section{sanction treatment reward treatment}

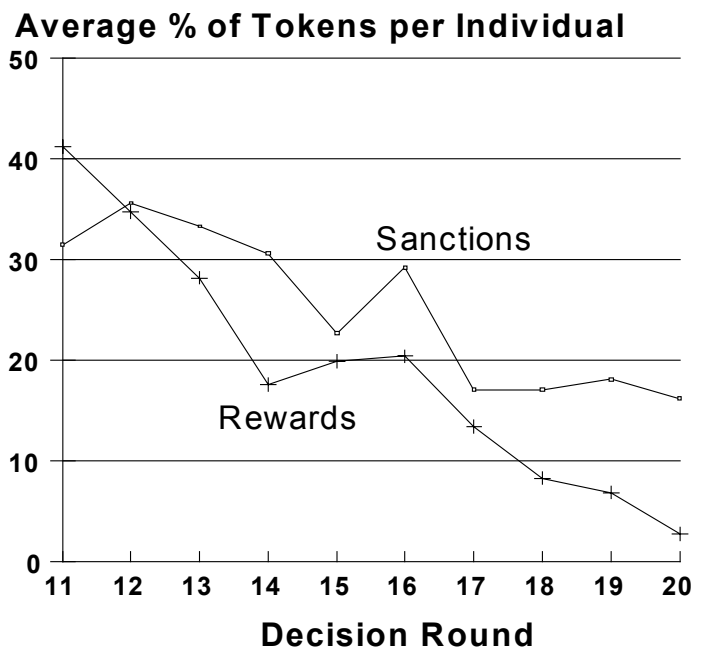

sanction \& reward treatment

Average $\%$ of Tokens per Individual

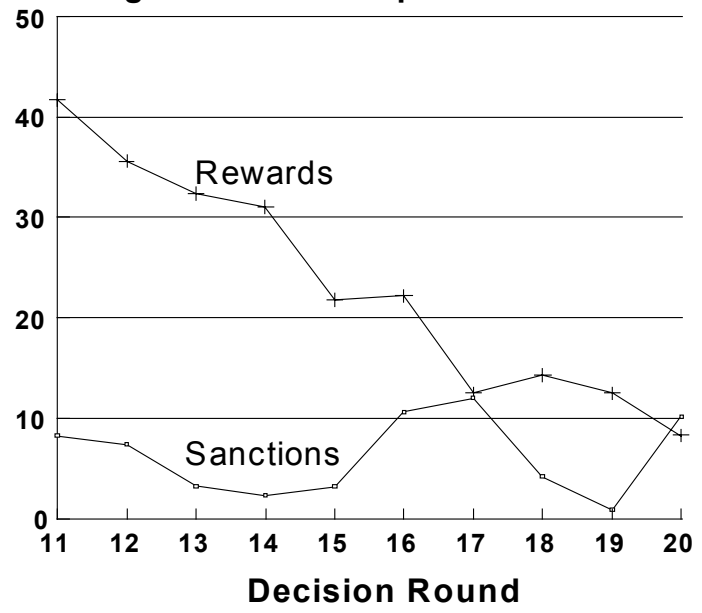


Figure 4. Net Reward Received in Relation to Deviation from Others' Average Group Allocation

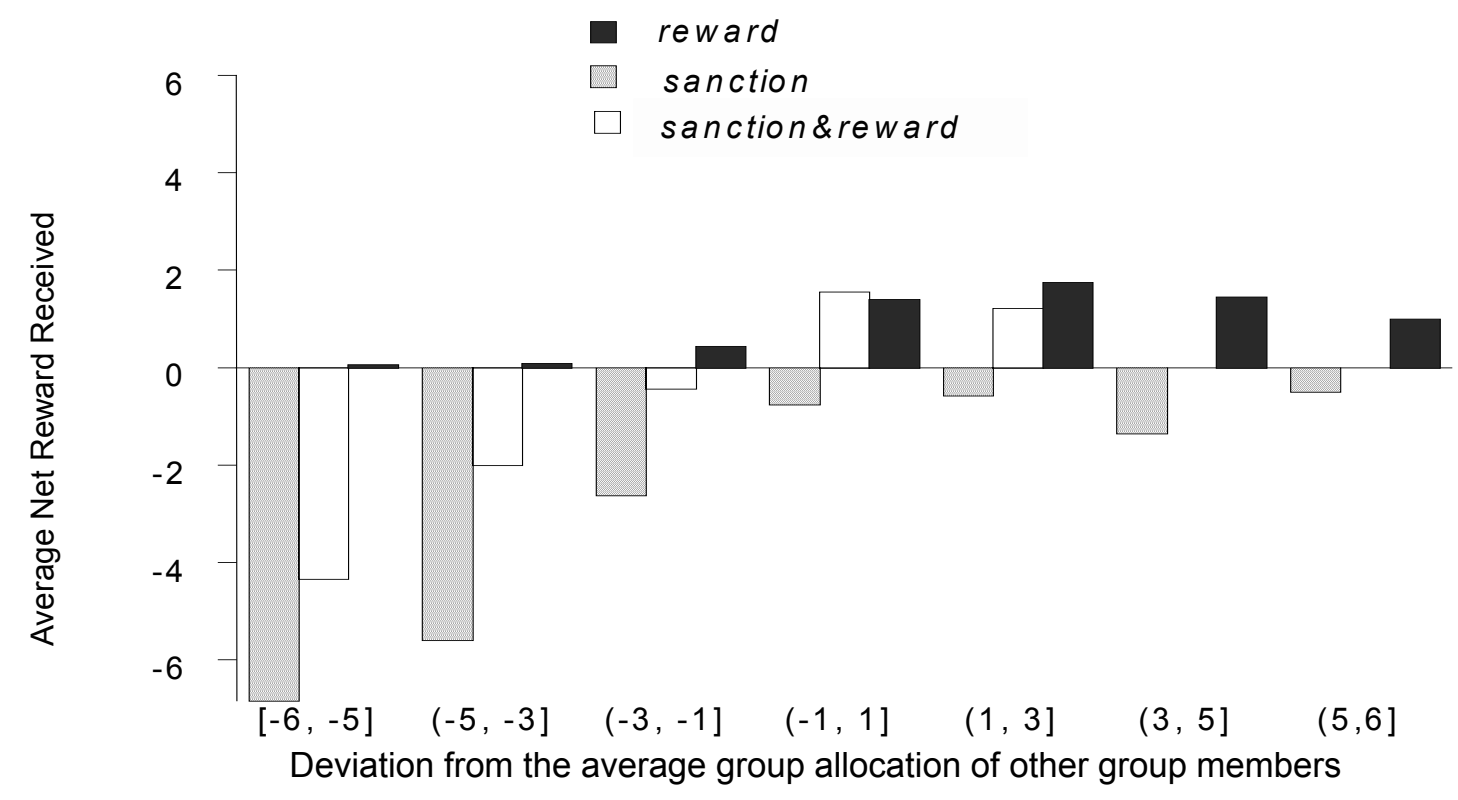




\section{Figure 5. Additional Experiments - 30 Rounds}
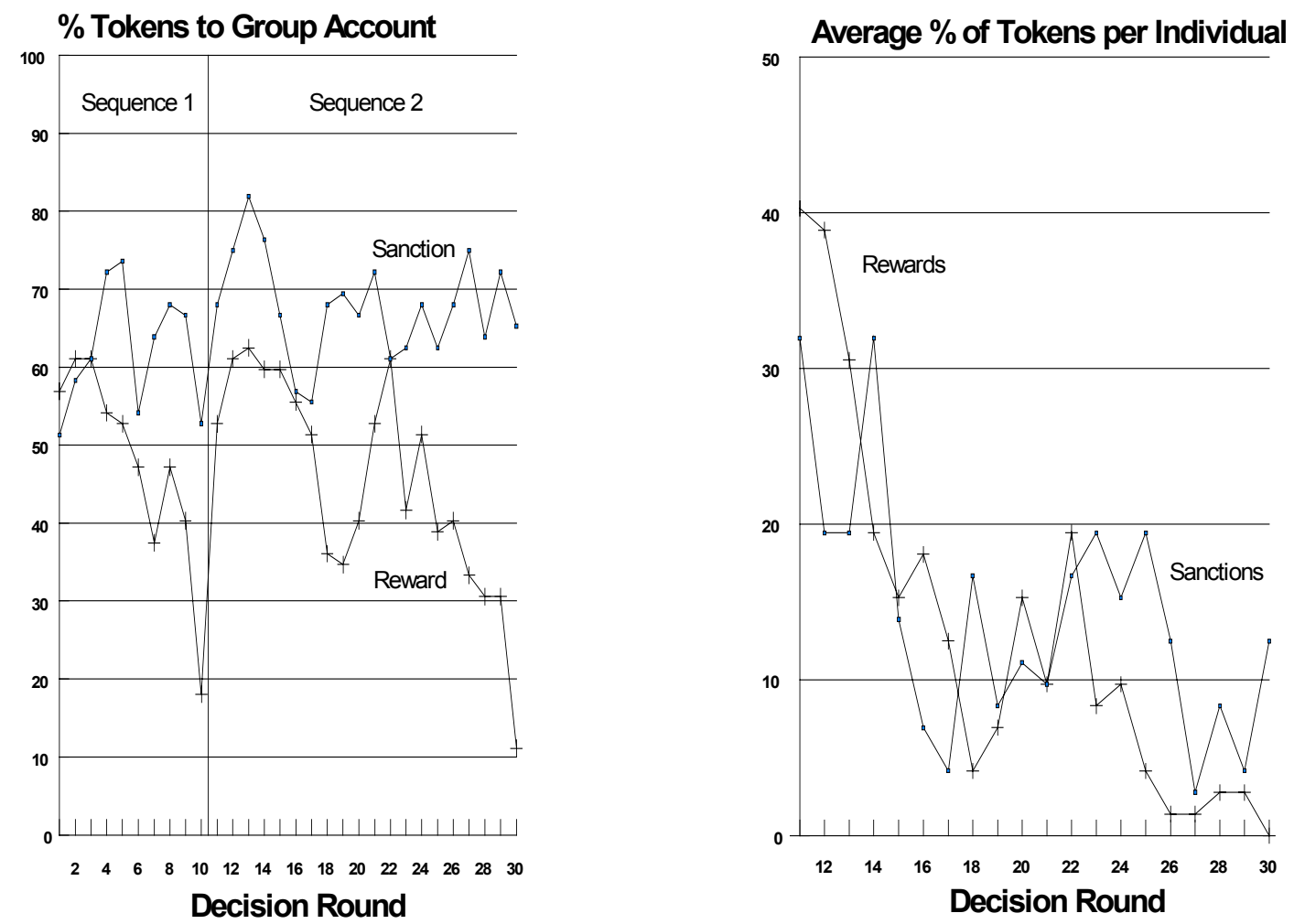


\section{Figure 6. Additional Experiments - Neutral Language Instructions}

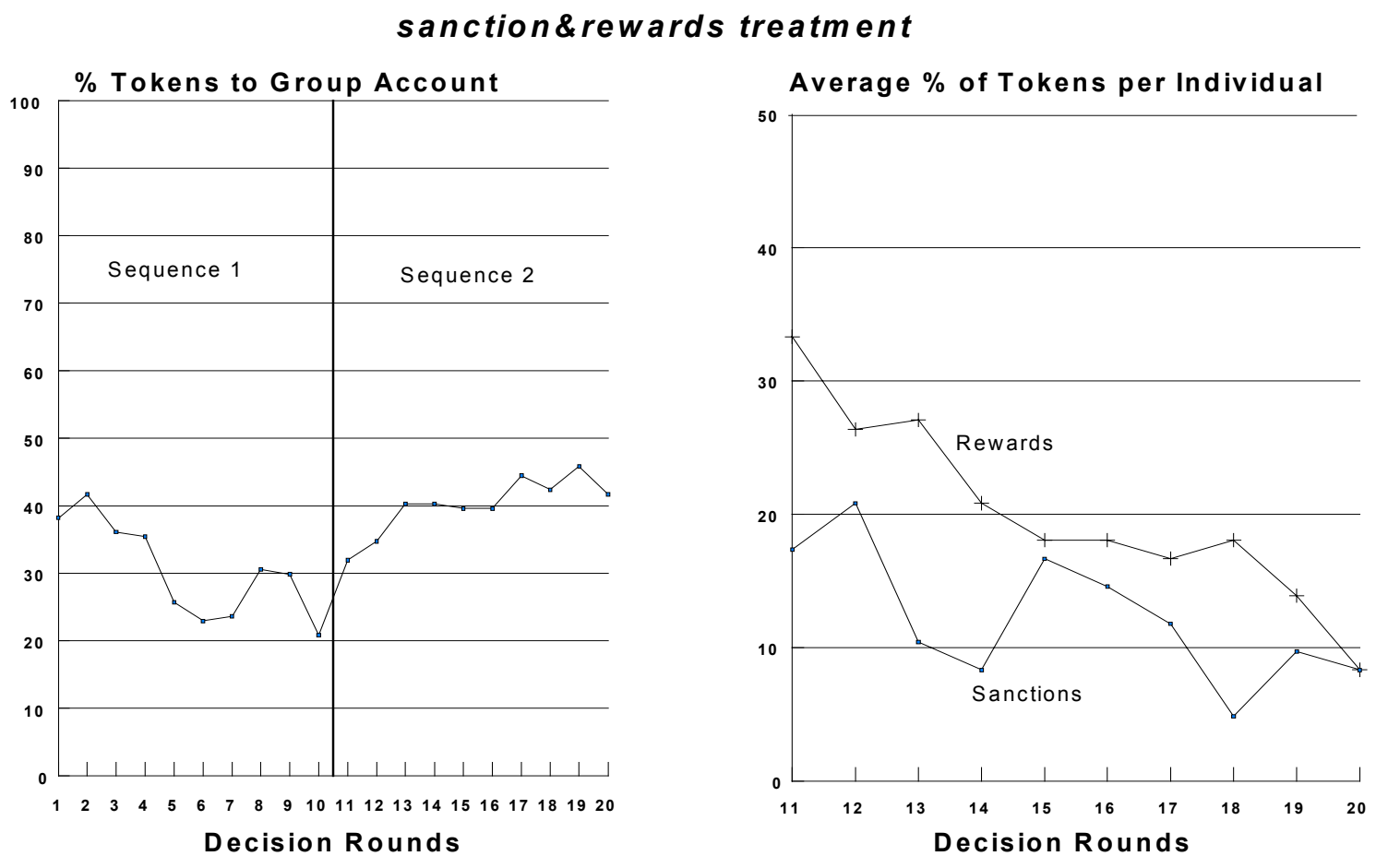




\section{Appendix I: Instructions}

Screen Prints from Instructions for sanction\&reward treatment. Changes made for neutral wording sessions indicated in [ ]. Instructions for the other treatments were very similar, variations only in regard to whether rewards only, sanctions only, or no rewards and sanctions were permitted.

This is an experiment about decision-making. Several research foundations have provided the funds for this experiment. The instructions are simple and if you follow them carefully and make good decisions you might earn a considerable amount of money which will be paid to you privately and in cash at the end of today's session. The amount of money you earn depends on the decisions that you and the other participants make. You will never be asked to reveal your identity to anyone during the course of the experiment. Your name will never be associated with any of your decisions. In order to keep your decisions private do not reveal your choices to any other participant.

\section{THIS EXPERIMENT}

This experiment consists of TWO SEQUENCES of decision rounds. EACH SEQUENCE CONTAINS 10 DECISION ROUNDS. You will be in a group of size four (you plus three other people). We have already randomly assigned you to a group. YOU WILL REMAIN IN THIS GROUP FOR THE REST OF THIS EXPERIMENT. However, you will not be told each other's identities. Your earnings will depend upon the decisions that you make and the decisions that the other people in your group make.

SEQUENCE 1 (decision rounds 1-10)

Each round you will be endowed with 6 tokens. You must choose how many of these tokens to keep in your PRIVATE ACCOUNT and how many tokens to allocate to a GROUP ACCOUNT. The amount of money that you earn in each decision round depends on how many tokens you place in your private account, how many tokens you allocate to the group account, and how many tokens the others in your group allocate to the group account.

You can choose any number of tokens to allocate to your private account, from 0 through 6 tokens, and any number to allocate to the group account (also any number from 0 through 6 tokens). However, the number of tokens you allocate to your private account and to the group account must sum to 6 .

You will earn 10 web-cents for each token you allocate to your private account.

For each token you allocate to the group account, you will earn 5 web-cents, and each of the other three people in your group will also earn 5 web-cents (a total of 20 web-cents for all four of you together).

For each token another person in your group allocates to their own private account, they also earn 10 web-cents.

For each token another person in your group allocates to the group account, this person will earn 5 web-cents, and each of the other people in your group will also earn 5 web-cents (a total of 20 web-cents for the group).

TO SUMMARIZE, in each of rounds 1-10 you will earn:

10 web-cents times the number of tokens you allocate to your private account PLUS

5 web-cents times the total number of tokens allocated to the group account by everyone in their group.

At the beginning of each round, you will see a screen like the one shown below.

You will enter an amount to allocate to the group account by clicking the "+1" and "-1" buttons. The amount allocated to your private account is the part of your endowment that is left after you have entered your group allocation amount. Once you have entered an amount, click the "Submit Allocation Decision" button and you will be 
asked to confirm your decision. If your decision is ok, click OK. If it is not, or you wish to change your decision, click Cancel. PLEASE TRY THIS NOW.

After all individuals have made their decisions for the round, the computer will tabulate the results. You will be informed of the total allocation to the group account and your total earnings for the round. You will also be informed of the allocation decisions of each member of the group. On your own screen your allocation decision will be listed first, and the other three decisions will listed in random order. Thus, information about individual decisions will be completely anonymous.

This same process will be repeated for a total of 10 rounds. Notice that you will have 6 tokens to allocate in each of the 10 rounds. Note that at the end of a round the decisions of the other people in your group are listed in random order. This means, for example, that the person listed second in one round may be different from the person listed second in another.

SEQUENCE 2 (decision rounds 11-20)

In the second sequence of decision rounds (rounds 11-20), each decision round will have two parts.

PART 1 of SEQUENCE 2: In the first part of the decision round, the type of decision you make will be just like the type of decision you made in rounds 1-10.

In part one of each round you will be endowed with 6 tokens.

You must choose how many of these tokens to keep in your private account and how many tokens to allocate to a group account. The amount of money that you earn in part one of each decision round depends on how many tokens you place in your private account, how many tokens you allocate to the group account, and how many tokens the others in your group allocate to the group account. You can choose any number of tokens to allocate to your private account, from 0 through 6 tokens, and any number to allocate to the group account (also any number from 0 through 6 tokens). However, the number of tokens you allocate to your private account and to the group account must sum to 6.

You will earn 10 web-cents for each token you allocate to your private account.

For each token you allocate to the group account, you will earn 5 web-cents, and each of the other three people in your group will also earn 5 web-cents (a total of 20 web-cents for all four of you together).

For each token another person in your group allocates to their own private account, this person will earn 10 webcents.

For each token another person allocates to the group account, this person will earn 5 web-cents,and each of the other people in your group will also earn 5 web-cents (a total of 20 web-cents for the group).

TO SUMMARIZE, in the first part of each of rounds 11-20 you will earn:

10 web-cents times the number of tokens you allocate to your private account PLUS

5 web-cents times the total number of tokens allocated to the group account by everyone in their group.

In each round in the second sequence, at the end of part 1 you will be informed of the total allocation to the group account and your total earnings for part 1 of that round. You will also be informed of the allocation decisions of each member of the group. On your own screen your allocation decision will be listed first, and the other three decisions will listed in random order. Thus, information about individual decisions will be completely anonymous.

PART 2 of SEQUENCE 2: 
In the second part of each round in the second sequence you will be endowed with 6 tokens.

You must choose how many of these tokens to keep in your private account and how many tokens to use to reward or sanction each of the other group members.

The amount of money that you earn in the second part of a round depends on how many tokens you place in your private account, and how many tokens the others in your group reward or sanction you.

In part 2 you can choose any number of tokens to allocate to your private account, from 0 through 6 tokens, and any number to reward or sanction other group members (also any number from 0 through 6 tokens for each other group member). However, the number of tokens you allocate to your private account and to rewarding or sanctioning other group members must sum to 6 .

You will earn $10 \mathrm{web}-\mathrm{cents}$ for each token you allocate to your private account. For each token you use to reward another group member, that group member will receive 10 web-cents. For each token you use to sanction another group member, that group member will lose 10 web-cents.

For each token another person in your group allocates to their private account, this person will earn 10 web-cents.

For each token this person uses to reward another group member, that group member will receive 10 web-cents. In particular, if another person in your group rewards you, you will receive 10 web-cents. For each token this person uses to sanction another group member, that group member will lose 10 web-cents. In particular, if another person in your group sanctions you, you will lose 10 web-cents.

TO SUMMARIZE, in part 2 of each round in the second sequence you will earn:

10 web-cents times the number of tokens you allocate to your private account PLUS

10 web-cents times the number of tokens the other group members reward you MINUS

10 web-cents times the number of tokens the other group members sanction you.

Your total earnings for the round will be the sum of your earnings from part 1 and part 2 of that round. It is possible for your earnings to be negative in a given decision round.

In part 1 of each round, you will decide how to allocate your tokens between your private account and the group account. You will then see the results from part 1 and move to part 2.

At the beginning of part 2, you will see a screen like the one shown below.

The first column of each row lists how many tokens another group member allocated to the group account in part 1 . The amount you enter in the two columns beside it is the number of tokens you wish to use to reward (first column) or sanction

Remember, in part 2 of each sequence 2 round you will have 6 tokens that can be allocated to your private account or used to reward and/or sanction the other players in your group.

As in part 1, you enter amounts by clicking the "+1" and "-1" buttons. Also as in part 1, the amount of tokens allocated to your private account is the amount of your endowment that is left after you have entered your reward and/or sanction amounts. Once you have entered these amounts, click the "Submit Reward/Sanction Decisions" button you will be asked to confirm your decision. If your decision is ok, click OK. If it is not, or you wish to change your decision, click Cancel.

Remember - In part 2, the number of tokens you allocate to your private account and the number you use to reward or sanction other group members must sum to 6 . That is, you can enter any number between 0 and 6 inclusive in any of the spaces in the table, but all the numbers you enter must add up to 6 OR LESS. 
After all individuals have made their decisions for the part 2 of each round, the computer will tabulate the results and you will be informed of your earnings from part 1, part 2, and the total for the round.

This same process will be repeated for all 10 rounds of the second sequence, that is, rounds 11-20. Notice that you will have 6 tokens to allocate in each part of each of the 10 rounds. Note that at the end of a round the decisions of the other people in your group are listed in random order. This means, for example, that the person listed second in one round may be different from the person listed second in another.

\section{EARNING MONEY IN THIS EXPERIMENT}

We will record your web-cent earnings in every round this experiment. At the end of the experiment we will add up these web-cent earnings and convert them to U.S. dollars by multiplying by 0.01 . We will pay you this amount privately and in cash. Your earnings are your own business and you do not have to discuss them with anyone.

During the experiment, you are not permitted to speak or communicate with the other participants. If you have a question while the experiment is going on, please raise your hand and one of us will come to your seat to answer it. At this time, do you have any questions about the instructions or procedures? If you have a question now or at any time during the experiment, please raise your hand and one of us will come to your seat to answer it.

Finally, a history screen with a summary of past decisions and earnings will be available. To see the history screen, click the "History" button at the bottom of your screen. To continue, you must click the "Close History" button at the bottom of the history screen.

Please click "Continue" to begin the experiment. 


\section{Appendix II: Group data - averages in terms of tokens per group member per round}

$\mathrm{B}$ refers to baseline, etc. $\mathrm{X}$ refers to extended time horizon. $\mathrm{N}$ refers to neutral language.

\begin{tabular}{|c|c|c|c|c|c|c|c|c|c|c|c|c|}
\hline Group & \multicolumn{6}{|c|}{ allocation to group account in round } & \multicolumn{3}{|c|}{ sanctions in round } & \multicolumn{3}{|c|}{ rewards in round } \\
\hline & 1 & 10 & Seq I & 11 & last & Seq II & 11 & last & Seq II & 11 & last & Seq II \\
\hline B1 & 2.75 & 1.25 & 2.375 & 3.00 & 1.25 & 1.725 & - & - & - & - & - & - \\
\hline B2 & 3.25 & 3.00 & 3.925 & 3.75 & 1.75 & 2.975 & - & - & - & - & - & - \\
\hline B3 & 5.00 & 3.00 & 4.375 & 3.25 & 0.50 & 2.250 & - & - & - & - & - & - \\
\hline B4 & 1.75 & 0.25 & 1.175 & 0.50 & 0.75 & 0.625 & - & - & - & - & - & - \\
\hline B5 & 2.25 & 3.00 & 2.250 & 3.00 & 2.00 & 3.350 & - & - & - & - & - & - \\
\hline B6 & 2.50 & 2.25 & 2.700 & 2.50 & 1.50 & 1.775 & - & - & - & - & - & - \\
\hline B7 & 4.75 & 4.00 & 5.325 & 5.25 & 5.00 & 5.175 & - & - & - & - & - & - \\
\hline B8 & 2.75 & 3.25 & 3.450 & 4.00 & 2.75 & 3.850 & - & - & - & - & - & - \\
\hline B9 & 3.00 & 1.75 & 2.650 & 2.50 & 1.00 & 1.525 & - & - & - & - & - & - \\
\hline S1 & 4.75 & 5.75 & 5.825 & 6.00 & 5.75 & 5.975 & 0.25 & 0.00 & 0.100 & - & - & - \\
\hline S2 & 2.75 & 3.00 & 2.850 & 2.00 & 4.50 & 4.150 & 3.00 & 0.75 & 1.600 & - & - & - \\
\hline S3 & 5.00 & 4.50 & 5.100 & 4.50 & 4.75 & 5.150 & 0.50 & 0.75 & 0.750 & - & - & - \\
\hline S4 & 3.00 & 3.25 & 2.825 & 3.50 & 1.75 & 2.400 & 3.00 & 1.50 & 1.800 & - & - & - \\
\hline S5 & 3.00 & 0.75 & 3.100 & 1.50 & 1.50 & 3.025 & 3.75 & 3.00 & 3.375 & - & - & - \\
\hline S6 & 3.00 & 1.50 & 2.525 & 2.25 & 0.25 & 1.350 & 0.75 & 0.00 & 0.250 & - & - & - \\
\hline S7 & 2.50 & 2.00 & 2.225 & 1.75 & 1.50 & 2.775 & 3.50 & 2.50 & 3.825 & - & - & - \\
\hline S8 & 5.25 & 4.50 & 5.300 & 4.50 & 6.00 & 5.325 & 1.00 & 0.00 & 0.725 & - & - & - \\
\hline S9 & 2.00 & 1.00 & 1.500 & 1.75 & 1.75 & 1.925 & 1.25 & 0.25 & 1.150 & - & - & - \\
\hline R1 & 2.00 & 2.25 & 2.050 & 2.25 & 1.00 & 2.775 & - & - & - & 2.50 & 0.00 & 1.250 \\
\hline R2 & 2.00 & 1.25 & 1.600 & 1.25 & 1.50 & 2.925 & - & - & - & 2.50 & 0.50 & 1.575 \\
\hline R3 & 4.75 & 4.25 & 5.100 & 5.75 & 4.5 & 5.300 & - & - & - & 2.25 & 1.00 & 0.850 \\
\hline R4 & 3.25 & 2.75 & 4.475 & 5.00 & 1.00 & 3.425 & - & - & - & 2.50 & 0.00 & 1.300 \\
\hline R5 & 2.00 & 0.50 & 2.225 & 2.25 & 2.25 & 3.025 & - & - & - & 3.00 & 0.00 & 1.350 \\
\hline R6 & 3.50 & 1.75 & 3.100 & 3.25 & 0.25 & 3.075 & - & - & - & 2.75 & 0.00 & 1.200 \\
\hline R7 & 2.75 & 3.00 & 4.150 & 5.00 & 0.00 & 4.300 & - & - & - & 3.50 & 0.00 & 0.975 \\
\hline R8 & 3.00 & 0.50 & 1.700 & 3.00 & 0.25 & 3.575 & - & - & - & 2.00 & 0.00 & 1.425 \\
\hline R9 & 3.00 & 3.25 & 4.375 & 4.75 & 0.25 & 3.700 & - & - & - & 1.25 & 0.00 & 0.525 \\
\hline RS1 & 3.25 & 2.75 & 2.750 & 4.00 & 2.50 & 4.250 & 0.75 & 0.75 & 0.750 & 2.75 & 1.50 & 1.925 \\
\hline RS2 & 3.50 & 2.75 & 3.525 & 2.75 & 5.00 & 4.350 & 2.00 & 0.00 & 0.525 & 0.75 & 0.25 & 0.550 \\
\hline RS3 & 4.00 & 3.00 & 4.350 & 5.25 & 4.50 & 5.625 & 0.00 & 1.75 & 0.175 & 2.25 & 0.00 & 0.900 \\
\hline RS4 & 4.25 & 3.50 & 4.900 & 4.75 & 4.50 & 5.675 & 0.50 & 0.25 & 0.125 & 2.50 & 0.50 & 1.850 \\
\hline RS5 & 3.50 & 3.50 & 3.075 & 3.75 & 3.75 & 4.025 & 0.00 & 0.00 & 0.250 & 2.75 & 0.00 & 0.875 \\
\hline RS6 & 3.75 & 6.00 & 5.675 & 5.75 & 4.50 & 5.675 & 0.25 & 2.25 & 0.525 & 5.00 & 0.00 & 3.150 \\
\hline RS7 & 2.00 & 1.00 & 1.400 & 1.50 & 2.00 & 2.000 & 0.25 & 0.00 & 0.400 & 1.75 & 0.00 & 0.500 \\
\hline RS8 & 2.50 & 2.25 & 2.325 & 1.50 & 2.00 & 2.425 & 0.50 & 0.50 & 0.325 & 2.50 & 0.00 & 0.575 \\
\hline RS9 & 3.00 & 3.50 & 3.750 & 3.50 & 6.00 & 5.175 & 0.25 & 0.00 & 0.300 & 2.25 & 2.25 & 2.225 \\
\hline SX1 & 4.50 & 2.00 & 3.400 & 3.75 & 2.50 & 3.388 & 2.00 & 1.50 & 1.000 & - & - & - \\
\hline SX2 & 3.75 & 5.50 & 5.200 & 5.75 & 6.00 & 5.613 & 1.75 & 0.00 & 0.400 & - & - & - \\
\hline SX3 & 1.00 & 2.00 & 2.600 & 2.75 & 3.25 & 3.200 & 2.00 & 0.75 & 1.163 & - & - & - \\
\hline RX1 & 4.25 & 1.00 & 4.275 & 5.50 & 0.50 & 1.888 & - & - & - & 4.00 & 0.00 & 0.700 \\
\hline RX2 & 2.75 & 1.25 & 1.475 & 1.25 & 1.00 & 2.238 & - & - & - & 1.25 & 0.00 & 1.050 \\
\hline RX3 & 3.25 & 1.00 & 2.825 & 2.75 & 0.50 & 4.025 & - & - & - & 2.00 & 0.00 & 0.600 \\
\hline RSN1 & 2.00 & 2.00 & 2.100 & 1.75 & 3.75 & 3.175 & 0.75 & 1.25 & 1.475 & 0.50 & 0.50 & 0.850 \\
\hline RSN2 & 2.25 & 2.25 & 1.925 & 2.25 & 1.75 & 1.400 & 1.25 & 0.50 & 0.500 & 2.50 & 0.25 & 2.025 \\
\hline RSN3 & 4.25 & 0.00 & 2.275 & 3.00 & 5.25 & 4.750 & 1.75 & 0.00 & 0.925 & 3.00 & 1.50 & 1.875 \\
\hline RSN4 & 2.00 & 1.75 & 2.075 & 2.00 & 2.25 & 2.175 & 0.75 & 1.00 & 0.800 & 2.25 & 0.25 & 0.725 \\
\hline RSN5 & 2.50 & 0.25 & 1.725 & 1.50 & 0.75 & 1.625 & 1.00 & 0.25 & 0.400 & 1.50 & 0.00 & 0.700 \\
\hline RSN6 & 0.75 & 1.25 & 0.875 & 1.00 & 1.25 & 1.300 & 0.75 & 0.00 & 0.325 & 2.25 & 0.50 & 1.050 \\
\hline
\end{tabular}




\section{Endnotes}

${ }^{1}$ See Ostrom (1990) for an insightful discussion of governance of common pool resources and the role of sanctions. Also see Kerr (1999) for evidence related to social exclusion and Carpenter (2000) for arguments for how the setting investigated here relates to particular types of team production problems.

${ }^{2}$ Recent experimental studies provide strong support for the role of norms of reciprocity in social dilemma settings. For examples, see Orbell, van de Kraght, and Dawes (1988), Isaac, Walker, Williams (1994), Sonnemans, Schram, Offerman (1999), Keser (1997, 1999), Croson (1998), Coats and Neilson (2000), Gunnthorsdottir, Houser, McCabe, and Ameden (2000), Clark and Sefton (2001), Schmidt, Shupp, Walker, Ahn, and Ostrom (2001), and Seely, Van Huyck, and Battalio (forthcoming).

${ }^{3}$ See Ledyard (1995) for a review.

${ }^{4}$ Also see Orbell, van de Kragt, and Dawes (1988) and Isaac and Walker (1988) for a discussion of the effectiveness of face-to-face non-binding communication as an institution for facilitating cooperation in public goods environments.

${ }^{5}$ Dickinson (2001) compares externally imposed prizes and penalties based on allocations to team outcomes. Players are rewarded or penalized based on their absolute efforts and on their efforts relative to other team members. He finds that the imposition of these incentives increase efforts, and by more than the amount of the prize/penalties. Falkinger, Fehr, Gächter and Winter-Ebmer (2000) also study an exogenously imposed mechanism that subsidizes (or taxes) a group member whose contribution to a public good falls short of (or exceeds) average contributions. These simple incentives are highly effective in inducing contributions.

${ }^{6}$ Students in introductory economics have majors in numerous disciplines including business, political science, journalism, and economics. Less that $5 \%$ are economics majors.

${ }^{7}$ See Appendix I for a copy of the instructions.

${ }^{8}$ Each session was completed in approximately one hour. Subject earnings averaged $\$ 28.91$ (which includes a $\$ 5$ participation fee).

${ }^{9}$ To enhance the degree of parallelism between the baseline and other treatments, we presented the twenty rounds of the baseline sessions in terms of two sequences of ten rounds, and in each round of Sequence II subjects received six additional tokens in their private accounts.

${ }^{10}$ In the sanction treatments there are other Nash equilibria, including some that support efficient allocations. However, equilibrium strategies that support efficient allocations rely on non-credible threats to sanction free riders.

${ }^{11}$ To explain this behavior, the theoretical literature focuses on factors within the game and those in the environment surrounding a particular play of the game that are posited to affect individual motivation and behavior. Recent modeling approaches have turned to representations of subjects' preferences beyond own pecuniary motivations. In addition to pecuniary payoffs, these models include subjects' orientations to altruism, fairness, or reciprocity. For examples, see Sugden (1984), Andreoni (1988), Bolton and 
Ockenfels (2000), Hoffman, McCabe and Smith (1998), Fehr and Schmidt (1999), and Falk and Fischbacher (forthcoming), Ahn, Ostrom, and Walker (2002).

${ }^{12}$ Although not targeted at specific individuals, reducing/increasing group allocations in the VCM game can be viewed as forms of sanctions/rewards imposed on others in the group. However, unlike the sanctions investigated here, individuals reducing group allocations in the stage game receive greater payoffs for themselves.

${ }^{13}$ See Appendix II for summary group-level data.

${ }^{14}$ Treating each group as an independent observation and averaging across decision rounds, an F-test of differences across treatments is not significant $(\mathrm{F}=0.18, \mathrm{n}=36, \mathrm{p}=0.907)$. A non-parametric KruskalWallis test supports this conclusion.

15 As Isaac, Walker and Williams (1994) demonstrate, the level and rate of group allocations in VCM games is strongly correlated with the marginal per capita return from the group account, as well as group size and number of rounds. Fehr and Gächter, in their partners treatment, with four-person groups and a marginal per capita return of 0.4 , find an overall average group allocation of $37 \%$ over 10 rounds and $18 \%$ in the final round. In a related study, with virtually identical parameters to our own, Swope (2002) finds an overall group allocation of $45 \%$ and a final round allocation of $23 \%$.

${ }^{16}$ Round $11(\mathrm{~F}=0.39, \mathrm{n}=36, \mathrm{p}=0.759)$, Round $20(\mathrm{~F}=4.87, \mathrm{n}=36, \mathrm{p}=.007)$, All Rounds $(\mathrm{F}=2.64, \mathrm{n}=36$, $\mathrm{p}=0.066)$. Non-parametric Kruskal-Wallis tests support these conclusions.

${ }^{17}$ Using a two-sided rank sum test Round $11(\mathrm{p}=0.6575)$, Round $20(\mathrm{p}=0.1558)$, All Rounds $(\mathrm{p}=$ $0.0851)$.

${ }^{18}$ Using a two-sided rank sum test Round $11(\mathrm{p}=0.3757)$, Round $20(\mathrm{p}=0.0101)$, All Rounds $(\mathrm{p}=$ 0.0133).

${ }^{19}$ Using a two-sided rank sum test Round $11(\mathrm{p}=0.6905)$, Round $20(\mathrm{p}=0.2313)$, All Rounds $(\mathrm{p}=$ $0.2004)$.

${ }^{20}$ An alternative specification would calculate efficiency as the increase in earnings over minimum possible earnings. In Sequence I, with no possibilities for sanctions or rewards, minimum possible group earnings occur when no tokens are allocated to the group account. Using this measure, the average efficiency was $56 \%$ in Sequence I, pooling across all 4 treatments. Finally, it is certainly the case that the gains from cooperation (increases in social welfare) may go beyond pure increases in pecuniary earnings.

${ }^{21}$ Comparing round 11 to round 20, the reward treatment yields an average decrease of $13.3 \%(\mathrm{t}=3.723$, $\mathrm{n}=9, \mathrm{p}=0.006)$, while the sanction treatment yields an average increase of $10.2 \%,(\mathrm{t}=2.393, \mathrm{n}=9$, $\mathrm{p}=0.044)$.

${ }^{22}$ Given that subjects had 6 tokens to use for sanctions/rewards, it is possible that some subjects, especially in early rounds, faced a binding constraint in their decisions to sanction or reward. Across all three treatments, however, in only 81 of 1080 decisions did a subject allocate all 6 tokens to either sanctions or rewards.

${ }^{23}$ Both of these studies suggest "blind revenge" as one possible motivation for this type of behavior. 
${ }^{24}$ Denoting own group allocations by $x$, and the average allocation of the other group members by $\bar{x}$, the variable absolute negative deviation is defined as $\max \{\bar{x}-x, 0\}$, and absolute positive deviation as $\max \{x-\bar{x}, 0\}$. Fehr and Gächter (2000) use sanction received as the dependent variable, so consistency with their reported results requires that our coefficients have the opposite signs.

${ }^{25}$ By treatment: sanction (range $=\$ 12.35$, var $=12.53$, and Gini $=0.116$ ), sanction $\&$ reward (range $=\$ 7.65$, var $=3.92$, and Gini $=0.0521)$, reward $($ range $=\$ 6.60$, var $=2.37$, and Gini $=0.0398)$, baseline $($ range $=\$ 5.00$, var $=2.19$, and Gini $=0.04)$.

${ }^{26}$ Using earnings that do not include sanctions and/or rewards (earnings after Stage 1) and earnings that do include sanctions and/or rewards (earnings after Stage 2), for individuals we computed the mean absolute deviation from average group earnings for each group in each round of sequence II, and averaged these over groups and rounds. By treatment: sanction (Stage $1=\$ 0.11$, Stage $2=\$ 0.14$ ), sanction\&reward $($ Stage $1=\$ 0.06$, Stage $2=\$ 0.15)$, reward $($ Stage $1=\$ 0.13$, Stage $2=\$ 0.200)$, baseline $($ Stage $1=$ Stage $2=\$ 0.10)$.

${ }^{27}$ Based on differences in implementation costs, Oliver (1980) develops an argument that sanctions will be more efficient in settings where near unanimous cooperation is required, while rewards will be more efficient if cooperation by only a small proportion of a group is required.

${ }^{28}$ Ostrom, Walker and Gardner (1992) show that the frequency of use of sanctions in a common-pool resource environment are inversely related to the cost of sanction and positively correlated with the magnitude of the sanction. The Ostrom, Walker and Gardner study finds little evidence that sanctions improve earnings net of sanction. In addition, Fehr and Gächter have recently conducted experiments examining the cost technology associated with rewards and sanctions. They find that when the ratio of the cost of being sanctioned to the cost of sanctioning is 1 to 1 group allocations display a slight downward trend, whereas when the ratio is 3 to 1 group allocations increase to near $100 \%$ (Gächter, personal communication).

${ }^{29}$ With this one-to-one sanctioning technology, a subject cannot use sanctions to reduce her earnings disadvantage relative to a free rider. However, coordinated sanctioning by the rest of the group could reduce a free rider's earnings advantage. 